\title{
ATIS Y TESEO: EL VIANE EN CATULO
}

Lia Margarila Galan

Universidad N. de La Plata

Resumen: Las trayectorias de Atis (Carmen 63) y de Teseo (Carmen 64) se presentan en Catulo como el desplazamiento entre dos mundos antagónicos y significan dos respuestas posibles al conflicto furor-ratio, como alternativas de hombre romano en el particular clima de crisis del fin de la República. El mundo del orden racional se identifica cin la civilización - Atenas -, mientras que lo irracional aparece representado por regiones signadas por lo monstruoso o lo salvage (los opaca nemora y el león de Cibeles, Creta y el Minotauro). El viaje implica dos modos de relación de estas formas antagónicas en las que se delinea el conflicto personal del poeta.

Palabras-clave: Atis, Teseo, Cibeles, Aridna, Lesbia, furor, ratio, civilización, anticivilización

Las relaciones entre el Carmen 63 y el Carmen 64 de Catulo han sido consideradas por la crítica de las últimas décadas sólo a partir de los nuevos presupuestos de interpretación de los llamados "carmina docta", que pueden sintetizarse asi:

a. estos poemas - en oposición a la crítica del siglo XIX, y aún del siglo $X X$ - son obras originales, la "gran poesía" de Catulo, modelada sobre diversas tradiciones como lo imponía la estética de su tiempo'

b. especialmente los Cármenes 63, 64 y 68 han interesado por su densidad psicologica, ya que en ellos se advierten conceptos y emociones que se enlazan profundamente con el llamado "ciclo de Lesbia", como una nueva dimensión a analizar de la conflictiva interioridad del poeta, que recurre en este caso al mito para expresarse; esto último ha producido complejos efectos ya que, si bien por un lado ha abierto nuevos campos de estudio - que inclyen la revaloración de estos poemas -, por otro lado ha llevado a cierto psicologismo de cuño freudiano que parcializa y limita sus significaciones ${ }^{2}$.

El Carmen 63 presenta el viaje de Atis y sus compañeros a los nemora de la diosa Cibeles con un fin consagratorio. La primera parte del poema (vv. 1-38) se

1. Al respecto, se destacan en especial las obras de Kenneth Quinn y Michael Putnam, entre otros.

2. Estos extremos pueden ejemplificarse con los estudios de Henri Bardon (Bardon, 1970) y Jean Granarolo (Granarolo, 1978) 
estructura sobre el discurso de Atis a los Gallae, quien, cumplida la castración ritual ${ }^{3}$, invita a sus compañeros a ascender a la domus de la diosa. Esta carrera culmina ante el templo:

Itaque, ut domum Cybelles tetigere lassulae, Nimio e labore somnum capiunt sine Cerere.

vv. 35-6

[Asl, cuando alcanzaron cansadas el templo de Cibeles, recibieron un sueño sin Ceres por la excesiva labor]

Bajo la luz del nuevo dia, Atis vuelve a la costa liberado momentáneamente del furor y, a solas, reflexiona sobre su nueva condición (Vv. 3973). Sólo a partir del segundo discurso de Atis se completan los datos de su trayectoria: si hasta el momento sólo se sabía que habla llegado a las costas de Cibeles en un viaje por mar (Super alta uectus Attis celeri rate maria, v. 1), ahora se sabe que este viaje significa el abandono de Atenas, ciudad en la que Atis era gymnasi... flos (v. 64), i. e. un joven que encarnaba el modelo de la urbanitas idealmente situado en la polis por excelencia.

El Carmen 64 presenta el motivo del viaje en los dos mitos más relevantes de la composición: el viaje de los Argonautas, esbozado apenas para enlazar el enamoramiento de Peleo y las posteriores bodas con Thetis, y el viaje de Teseo a Creta, incluido en la écphrasis del cobertor a partir de la imagen de Ariadna abandonada. Se han realizado estudios comparativos entre los personajes de Atis y Ariadna, basados en cierta comunidad de emociones y situaciones que hacen lícita, al menos en modo general, su asociación; ellos presuponen la fuerte ingerencia del elemento autobiográfico, según lo cual ambos resultan expresiones de la propia situación del poeta y su conflicto emocional. Frente a esto, entendemos que resulta particularmente esclarecedora la comparación entre Atis y Teseo, relación que puede establecerse sin violencias, dados los numerosos puntos de contacto que ambos presentan.

También Teseo parte de una Atenas que, al igual que en el Carmen 63, representa el polo de la civilización por excelencia, y viaja a Creta por su propia voluntad, aún a riesgo de que se trate de un viaje sin retorno:

Ipse suum These us pro caris corpus Athenis proicere optauit potius quam talia Cretam funera Cecropiae nec funera portarentur.

v. $81-3$

3. En rigor, los rituales romanos de Cibeles consistran en ceremonias que preparaban la castración, llevada a cabo el tercer dla de celebración llamado sanguen o dies sanguinis. No parece tratarse aqui de un intento por reflejar este ritual, ya que en el Carmen 63 el orden de las acciones aparece invertido, por cuando la castración se presenta al inicio de la ceremonia. 
[El mismo Teseo deseo ofrecer su cuerpo por su querida Atenas antes que funeral tras funeral de Cecropia fuera llevado a Creta]

Al igual que Atis, aunque con profundas diferencias, Teseo cumple su cometido y puede regresar a la polis, pero su hazaña se enluta por la muerte de Egeo que a su vez es la pena por la desmemoria en la que incurre con respecto a Ariadna:

Sed funesta domus ingressus tecta paterna morte ferox These us, qualem Minoidi luctum obtulerat mente immemori, talem ipse recepit.

v. 246-8

[Pero el fiero Teseo, ingresando a la casa paterna cubierta por la funesta muerte, cual habla llevado el luto a la hija de Minos, tal él mismo recibio.]

El esquema básico sobre el que se diseñan ambos mitos es el del viaje entre dos extremos, el desplazamiento desde la civilización al mundo de la oscuridad, lo salvaje y lo monstruoso.

En Atis esto se hace completamentemente explicito a través de los dos monólogos del personaje en el que se contraponen lo luminoso-racional de Atenas y lo oscuro-irracional, el mundo del furor situado en los opaca nemora de Cibeles en donde el personaje queda confinado. Asl, se establece la oposición ratio-furor con una localización precisa (Atenas - los nemora de Cibeles) y una separación irresoluble, el mar, que ha permitido el pasaje pero que impide el regreso y se constituye en símbolo de esta separación.

En el Carmen 64, estos mismos elementos se enlazan de modo más complejo y no hay una oposición explícita de los dos mundos en los que se desplaza el personaje de Teseo. Esto no significa, sin embargo, que tal oposición no se encuentre; se podría, aún, decir que sólo a partir de esta oposición puede hacerse más inteligible la trayectoria de Teseo.

Como Atis, Teseo deja Atenas por su propia voluntad (cf. v. 81: ipse... Theseus) y en este primer punto de contacto también puede observarse la primera gran diferencia, aquélla que marcará la radicál oposición de ambos destinos. Teseo abandona Atenas con la bendición de la diosa (sancti... incola Itoni, v. 228) y de su padre, y su decisión de ir a Creta no está impulsada por el furor sino que responde a la naturaleza tradicionalmente heroica del personaje.

Por el contrario, los datos que se consignan acerca de la partida de Atis de Atenas están determinadas por el furor y los movimientos que le corresponden, de índole marcadamente anti-heroica. Frente a la protección de Atenea que acompaña a Teseo, Atis abandona Atenas Veneris nimio odio (v. 17), esto es, una relación de orden negativo con respecto a su lugar de proveniencia. Más adelante se suma un segundo elemento: 
Patria o mei creatrix, patria mea genetrix, ego quam miser reliquens, dominos ut erifugae famuli solent, ad Idae tetuli nemora pedem... vv. 50-2

[patria, oh mi creadora, patria madre $\mathrm{ml}$, a quien yo $\mathrm{m} / \mathrm{sero}$ dejé, como suelen los esclavos huir de su amo, para llevar el paso hacia los bosques de Ida]

Atis ha huldo como un esclavo - después parece reconocerlo - de una comunidad en la que ha estado armónicamente integrado.

Asi, pues, ambos personajes se desprenden por propia voluntad del lugar en el que naturalmente se desarrolla su existencia para lanzarse al mar y afrontar diversa suerte de peligros; el viaje representa el desplazamiento entre opuestos, el movimiento del hombre entre mundos antagónicos. Atis y Teseo cruzan el mar (cifra de lo desconocido y de lo peligroso), y arriban a un lugar que, antes o después, resultará hostil: para Teseo desde el momento mismo del inicio de su empresa; para Atis este nuevo lugar, buscado por impulso del furor, será inhóspito en el momento en que tal furor ceda paso a la ratio y pueda considerar objetivamente sus actos.

\section{Atenas y La Vida de La Civilización}

Estos personajes están ligados a Atenas por un sentimiento de profunda pertenencia. Teseo expone su vida pro caris... Athenis (v. 81), movido por su feruida uirtus (v. 218), mientras que Atis se lamenta de haber abandonado una ciudad que es patria, creatrix y genetrix (v. 50).

¿Qué notas distinguen inequívocamente la Atenas ideal que nos presenta Catulo? En ella se sitúa un tipo de vida caracterizado por valores racionalmente reconcibles; en el caso de Teseo, es singularmente significativo el discurso de su padre Egeo y la misma decisión del héroe: Teseo debe poner en juego su vida para salvar a la ciudad, y lo hace movido por su feruida uirtus, Egeo debe sacrificar algo más precido aún que su vida, la vida de su único hijo:

Gnate mihi longe iucundior unice uita, gnate, ego quem in dubios cogor dimittere casus

$$
\text { v. 215-6 }
$$

[Hijo único más querido para ml que la vida, hijo, a quien me veo obligado a lanzar hacia dudosos peligros]

Sentimientos y humanos temores son depuestos en aras de la polis, en función del bien común que así lo demanda.

Para Atis, Atenas ha significado la posibilidad de una existencia íntegra y ordenada, que se quiebra con la irrupción del furor, esto se evidencia en la tardía añoranza de un modo de vida que le hacía abandonar el lecho al alba para dirigirse al gymnasium, aún cuando sus umbrales aparecieran sembrados de guirnaldas, 
emblema de una vida cortés que Atis ha desatendido para probarse en la palestra y otras disciplinas corporales u ocuparse de las actividades del foro (vv. 59-67).

\section{LA VIDA DE LA ANTI-CIVILIZACIÓN}

Atravesando el mar, Teseo llega a Creta cuyo signo es el Minotauro, i. e. lo monstruoso que ha generado el lugar según su misma naturaleza. Creta se dibuja así como una anti-civilización, la ciudad que gobierna Minos, presentado como iniustus rex (v. 75), donde imperan el pathos y la crueldad. Ariadna, la doncella real que será su representante, aparece en un muelle lecho de perfumes, cobijada por su madre -i. e. Pasifae -; y el súbito enamoramiento no está condicionado por ninguna divindad:

Hunc simul ac cupido conspexit lumine uirgo regia, quam suauis exspirans castus odores lectulus in molli complexu matris alebat, ...concepit corpore flammam v. $86-8$ funditus atque imis exarsit tota medullis. vv. $92-3$

[En cuanto lo contempló con mirada ávida la virgen real, a quien un pequeño lecho casto, que exhalaba suaves perfumes, hacla crecer...concibio una llama en todo su cuerpo, abrasándola profundamente toda en sus entrafias]

La pasión lleva a Ariadna a desear el triunfo del enemigo de su ciudad y de su familia, y aún a rogar a los dioses por el triunfo de la empresa que implica la muerte de su propio hermano ${ }^{4}$.

En este reino del pathos que constituye Creta, puede ocurrir la traición de Ariadna cuya relación filial se opone directamente a la de Teseo; mientras Ariadna trama la ayuda a Teseo movida tan solo por la pasión amorosa, lo cual significa la derrota de su ciudad y la traición a su padre, Teseo actúa en concordancia con los valores paternos y en servicio de su propia ciudad. Ningún sentimiento que no sea el patriótico o el heroico se antepone a lo que el deber requiere:

cum saeuum cupiens contra contendere monstrum aut mortem appeteret Theseus aut praemia laudis.

v. 101-2

[cuando deseando contender contra el monstruo cruel, Teseo apetecla la muerte o los premios de la alabanza.]

4. Esta problemática, si bien puede resultar algo bizarra, aparece en boca de la misma Ariadna cuando, abandonada, se autoacusa de haber ayudado al matador de su hermano", el Minotauro (... et potius germanum amittere creui, v. 150; respersum iuuenem fratema caede secuta?, v. 181. 
Resulta asimismo interesante constatar que el personaje que se destaca de este mundo de la anti-civilización es una mujer, con quien Teseo se relaciona sin deponer por ello el imperativo de su empresa ${ }^{5}$. La significación de este mundo de la anti-civilización se concentra en un personaje femenino, Ariadna, que encarna la imagen del furor. indomitos in corde gerens Ariadna furores (v. 54), (Ariadna) concepit corpore flammam (v. 92), incensam...puellam (v. 97), illam...ardenti corde furentem (v. 124), ...inops, ardens, amenti caeca furore (v. 197).

Para Atis, más allá del mar, se encuentran los bosques de Cibeles, y ya la misma naturaleza agreste del lugar - que Atis supone habitado por fieras ${ }^{6}$ - se presenta en directa oposición a la urbanitas ateniense. El viaje lleva al personaje a insertarse en el mundo de una divindad femenina y despotica, que atrae devotos enajenados y los precipita en la esclavitud irrenunciable del furor. AsI, cuando Atis recupera la razón y se lamenta de lo hecho, es la misma Cibeles quien le envía el león para que recuerde a Atis su condición inmutable de consagrado: esta irracionalidad será su condena y los restos de razón que aún le restan sólo contribuyen a hacer más dramática esta irreversible situación.

Teseo y Atis se desplazan dentro de estos dos mundos que representan alternativas reconocibles, ya que condensan conceptos de profunda significación en la cultura grecolatina.

Hacia el tiempo de Catulo, la contraposición se ha ido profundizando transformada, por sobre todo, en un antagonismo entre lo romano y lo oriental, tomados como modelos que disputarán la supremacía, y cuya tensión máxima puede ubicarse en las guerras civiles con el enfrentamiento de Octavio y Marco Antonio.

Aún cuando la poesía de Catulo eluda la directa ingerencia en problemas públicos contemporáneos - al menos en los poemas extensos -, no por ello puede reducirse a una especie de ejercicio o juego retórico sin referencias a la propia realidad situacional. En especial cuando la clave de lectura de estos poemas parece encontrarse no meramente en el mundo privado-psíquico del poeta, sino en el clima espiritual del fin de la república en el que es posible esta problemática. Los nuevos comportamientos sociales - cuyo origen es posible rastrear en las ciudades helenísticas, y de oriente medio - se implantan en una Roma convulsionada provocando una marcada reacción, luchas políticas, religiosas y morales que caracterizan la crisis de este tiempo. Ya el ciclo completo de los poemas de Lesbia presupone un nuevo modo de plantear la relación amatoria, y el programa del amor romántico es una evidencia de esta problemática. Los poemas dedicados a Lesbia traen una y otra vez el motivo recurrente de la pugna de valores en los que se acredita la relación amorosa, y en tal sentido es evidente la oposición que existe entre el vivamus (con el rechazo a las murmuraciones de los senum seueriorum,

5. No se habla del enamoramiento de Teseo, y los motivos que lo mueven a aceptar o requerir el viaje de Ariadna; Catulo tampoco ofrece razones para el abandono de Ariadna, y las acusaciones contra el héroe se ponen en boca de la mujer en fuerte estado de conmoción pasional. Hay en ella un despliegue de emociones que tambien se produce en el caso del discurso de Egeo. Contrariamente, no hay referencias directas de la interioridad de Teseo.

6. ....ad Idae tetuli nemora pedem, ut apud niuem et ferarum gelida stabula forem

et earum omnia adirem furibunda latibula, . . vv. 52-55 
C. 5, 1-2) y el especial compromiso del aeternum hoc sanctae foedus amicitiae (C. 109,6); reiterada, asimismo, es la oposición entre el amare pasional y el bene uelle que representa una valoración emparentada con lo racional ${ }^{7}$. Catulo refleja en el mundo de su existencia privada un conflicto que pertenece profundamente al seno de la sociedad romana, con sus nuevas conquistas, con sus nuevos y calificados huéspedes que, para muchos, amenazaban con hacer de Roma una provincia cultural de Alejandría. Esta forma, dirlase tal vez, de "penetración ideológica" inquietaba a sectores del patriciado que veían discutido un poder que consideraban poseer de modo legítimo. Los propios valores - identificados con los valores tradicionales de Roma, i. e. el discurso de quienes históricamente hablan detentado el poder -, conocidos por transmisión generacional, deblan ser revitalizados y actualizados para oponerlos a los que prestigiaban nuevos extranjeros que, directa 0 indirectamente, aspiraban a ocupar el poder.

Estas consideraciones, que seguramente incluirían argumentaciones acerca de problemas planteados en el patriciado (como la confrontación occidenteoriente, antiguo-moderno, etc. según se observa en los textos conservados), sin duda también ocupaban el retiro de los otiosi, i. e. de la intelectualidad vanguardista de su tiempo, para quienes es posible que el traslado de cuestiones públicas al ámbito personal y privado fuera un movimiento habitual, una especie de tópico de la conversación.

AsI, puede considerarse que Catulo está expresando una problemática general histórica acotada por el elemento personal. Esta problemática compromete un sector más amplio y complejo de la realidad, que excede necesariamente la experiencia particular y que obliga, por ello, a proyectar tal caso particular al orden de lo general, con el cual se corresponde directamente. Puede decirse, entonces, que Catulo analiza su propio conflicto proyectándolo sobre los valores generales de su tiempo, sometidos entonces a luchas de acreditación.

La trayectoria de Atis y Teseo muestran, ante todo, la voluntad de diseñar una problemática particular en el marco de representación de la época, entendido esto último como intento por presentar el conflicto sub specie aeternitatis. La problemática, de este modo, se plantea a partir del conflicto masculino-feminino; occidente-oriente; tradicional-nuevo; paz-guerra; razón-pasión, en torno a los cuales el poeta delibera. Atis y Teseo son estudiados bajo esta perspectiva, y significan posibles respuestas, con el encadenamiento necesario, al orden de los cuestionamientos propuestos.

Atis compromete su existencia con el furor, la elección que lo lanza al viaje significa la voluntaria comunión con una de las alternativas posibles. El furor lo lleva a dejar un mundo sentido como hostil [nimio odio Veneris] y opresivo [sentimiento de esclavitud, erifugae famuli] para habitar el mundo selvático de la diosa. AsI, el viaje explicita el corte, la quiebra que se produce ya con anterioridad y que obliga a cambiar una existencia por otra. Pero la lucha de valores no se resuelve: Atis, inmerso en el mundo femenino de Cibeles, no puede ser más que notha mulier (v. 27), y resignarse a una condición de famula de la que él, aún tomada en contexto distinto, ha huldo. El viaje no tiene regreso y Atis se autocontempla en su trágica dualidad, en una sumisión al furor que no alcanza a 
borrar la ratio ni la conciencia de su depuesta masculinidad [ego mei pars, ego uir sterilis ero?, v. 69].

Teseo cumple con el programa heroico, y en este sentido el viaje es la consumación de las pruebas a las que debe someterse ${ }^{8}$. También, como a Atis, una nave lo lleva al mundo del furor, simbolizado primeramente por el Minotauro; va hacia él como campeón de la virtus, como estandarte de la racionalidad ateniense. Logra vencer al monstruo, y obtener los praemia laudi, pero este furor se reviste de formas más sutiles ya que es la violencia pasional de la mujer quien lo compromete. El abandono de Ariadna no está justificado, y se callan sus razones; creemos que la versión está en relación con la que más tarde Virgilio dará de Eneas y Dido. Ariadna pertence, como Dido, al otro mundo, y su inserción armónica en la realidad ateniense resulta imposible. La uirtus de Teseo es imcompatible con la pasión, y en este caso se da la respuesta de la ratio; tampoco ésta es satisfactoria, ya que el furor aparentemente desterrado reclama un castigo que, concedido por Júpiter, enluta la casa del héroe.

Entendemos que Atis y Teseo simbolizan alternativas del hombre romano ya planteadas en el tiempo de Catulo - y posteriormente documentables en la poesía elegíaca -: los reclamos de la pasión frente a los imperativos racionales inscriptos en un orden cívico y legal que se ha vuelto cuestionable. Catulo no parece hallar una síntesis para esta condición antitética: como el poeta, los personajes transitarán por mundos que no pueden ser reconciliados.

\section{Bibliografia Selecta}

ARKINS, B. The originality of Catullus. LCM 3, 1978, 65-69.

BALSDON, J. P. V. D. Life and leisure in Ancient Rome. London, The Bodley Head, 1969.

BARDON, H. Propositions sur Catulle. Bruselas, Latomus, 1970.

CURRAN, L. Catullus and the heroic age. YCIS 21, 1969, 171-192.

DANIELS, M. L. Personal revelation in Catullus LXIV. CJ 62, 1967, 351-6.

ELDER, J. Catullus' Attis. AJPh 68, 1947, 394-403.

FORSYTH, P. Y. Catullus: the mythic persona. Latomus 35, 1976, 555-566.

GRANAROLO, J. Catulle ou la hantise du moi. Latomus 37, 1978, 368-386.

HARKINS, P. Autoallegory in Catullus 63 and 64. TAPhA 90, 1959, 102-116.

KNOPP, S. Catullus 64 and the conflict between amores and uirtutes. CPh 71, 1976, 207-213.

PUTNAM, M. The art of Catullus 64. HSCP 65, 1969, 850-7.

QUINN, K. The Catullan revolution. Cambridge, Heffer \& Sons, 1969.

SYNDIKUS, H. P. Catull: eine Interpretation. Darmstadt, Wiss. Buchges., 1990 [Tomo 2: los poemas extensos (61-68)].

8. Según esto, resulta explicable que Virgilio modele las escenas del Libro IV de la Eneida sobre la relación Teseo-Ariadna; también Eneas deberá abandonar a la mujer presa del furor para cumplir con su destino patriótico. 